\title{
The Use of Life Narrative and Living Standard Measurement Survey Data in the Study of Poverty in the Caribbean: A Resolution of Conflicting Epistemologies
}

\author{
Dennis A. V. Brown \\ Faculty of Social Sciences, University of the West Indies, St. Augustine, Trinidad and Tobago, West Indies \\ Email: Dennis.Brown@sta.uwi.edu
}

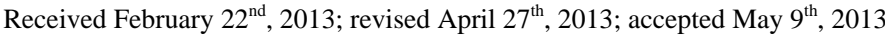

\begin{abstract}
Copyright (C) 2013 Dennis A. V. Brown. This is an open access article distributed under the Creative Commons Attribution License, which permits unrestricted use, distribution, and reproduction in any medium, provided the original work is properly cited.
\end{abstract}

\begin{abstract}
The paper examines the compatibility or usefulness of fit between epistemologically disparate quantitative survey data and qualitative life narrative data gleaned in the study of poverty in the Caribbean. It aims to find out whether or not the different approaches to the understanding of "reality" on which the two methodologies are based preclude the integration of their findings as a means of furthering understanding of the dynamics of Caribbean poverty. The analysis draws on Country Poverty Studies conducted in the territory of Grenada in the Eastern Caribbean. It is centered on the demographic measure of fertility, a measure of chronic illnesses by socioeconomic status and life narrative interviews conducted around the themes of poverty, family and life experiences with select poor households across the country. Fertility was measured using parity of women aged $<15-30+$. Statistical analyses were done using cross tabulations. The findings indicate that the hermeneutic understanding of the life narratives, and the causal explanatory accounts provided by the positivist quantitative data, allow for understanding of negative health seeking behaviour on the part of the poor, not provided by the quantitative data by themselves. They also provide insight into the synergy between family, reproductive behaviour, labour market status and chronic poverty in the Caribbean region that would not have been possible through the use of the positivist quantitative method by itself.
\end{abstract}

Keywords: Quantitative Data; Life Narrative Data; Epistemology; Caribbean Country Poverty Studies; Living Standard Measurement Surveys

\section{Introduction}

One of the features of the Development era beginning in the immediate post war period of development has been the misapplication of theories formulated in the North to the circumstances of the South in the interest of achieving ideological objectives (Rist, 2003: p. 109). The work of W. W. Rostow probably best exemplifies this tendency (Rostow, 1960). This provided the analysts from the North with something of a monopoly of knowledge deemed relevant for the formulation of public policy (Preston, 1996). Such an approach to the study of social phenomena was facilitated by positivist epistemology with its disregard of the influence of community and the local culture that informs it.

The introduction of qualitative methodology, based on its quest to understand meaning within the local context, into the research that informs this policy therefore reflects a shift in the asymmetry that has characterized the relationship between theorists and technocrats from the North and the South. Still, old habits die hard. Many of the local technocracy, at worst, stoutly resist the use of this type of data to inform social policy and its analysis, or, at best, express dissatisfaction with the fact that they cannot generalize the findings based on this type of research. This position seems to betray an inflexible adherence to methodological canons rather than a willingness to creatively apply them in the furtherance of our understanding of social phenomena.

The paper, firstly, examines methodological issues related to the collection and analysis of data on poverty using quantitative and qualitative approaches. Secondly, it looks at the institutional framework within which the ascendancy of positivist empiricism in the study of poverty occurred. This was defined by the managerial and political imperatives of an ascendant economic neoliberalism, itself an outcome of reaction against the populist, state-led approaches to development that characterized the immediate post independence era in the region. Thirdly, it considers the case for qualitative, hermeneutic approaches that have emerged out of some of the more recent debates on the changing global dynamics and the role of development theory and practice within it. Against this background, analysis of the two types of data is conducted. Here, an effort is made to see to what extent a meaningful complementtarity obtains, which extends our understanding beyond that 
which is possible by using only the traditional positivist approach.

\section{Methodological Issues}

\section{The Research Question}

The primary question posed by this paper is, given the epistemological disparateness of the two types of data, to what extent are quantitative and qualitative data derived from Living Standards Measurement Surveys (LSMS) in the Caribbean complementary and compatible with each other? Are the data and the findings they represent best treated by themselves and used to provide information on the areas from which they have been gleaned or, are there ways in which the data can be used together to provide us with understandings of social conditions that would not have been possible had they been used by themselves?

\section{Data Sources: Quantitative}

The quantitative data used in this paper are taken from the LSMS conducted in Grenada in 2008 (Caribbean Development Bank, 2008). The LSMS consists of a household-based Survey of Living Conditions (SLC), a Household Budgetary Survey (HBS) and an Institutional Analysis (IA). The household based components of the survey collect data on household composition, migration, age, sex, fertility (women aged 15 - 49), ethnicity, consumption levels, education, health, labour force status, social welfare and household expenditure on essential items. Whereas the SLC data are collected on the basis of the ability of one member of the household to recall information on all of the members of the household, the HBS data on expenditure are collected using the diary method. This entails the keeping of records of their expenditure by all members of the household. The data collected from both instruments complement each other and provide the basis for the derivation of consumption groupings and poverty estimates of the population.

\section{Data Sources: Qualitative}

The qualitative data gleaned from the survey came from the community-based Participatory Poverty Assessment (PPA) conducted in Grenada in 2008. This component of the survey consisted of community mapping, focus group discussions and indepth interviews of selected poor and non-poor households. It is this latter data source that provides the basis for the qualitative analysis that informs the research.

The sampling procedure that underlies the selection of these households was first of all purposive. Within this genre of sampling the intensity sampling approach that seeks out information was used. This seeks out rich cases that manifest the research variable in an intense way. This is also a form of theoretical sampling since the criteria used to select the cases are informed by a theory of poverty in the region that has emerged out of research done across the region (Brown, 2011: p. 207).

Using this approach I have come up with a preliminary hypothesis that suggests that Caribbean poverty is, in the main, intergenerational and that this transmission across the generations is sustained by deep structural inequalities in the way in which the society is organized, that is, in the distribution of tangible and intangible resources. At the level of proximate cause however there is a readily identifiable synergism of fac- tors that act as a transmission belt of poverty across the generations. These include mating and family formation patterns, low educational levels and lack of preparation for the labour market. Furthermore, the effects of these factors are mediated by gender, that is, they affect men and women differently.

The sampling procedure used therefore departs from the usual reliance on statistical probability sampling that controls for selection bias as a means of ensuring the representativeness of sample to population. In purposeful, intensity, theoretical sampling, bias is no longer a shortcoming but rather a means of ensuring the selection of cases loaded with information that allow for deep understanding rather than empirical generalization (Patton, 2002: p. 230).

\section{Collecting the Data: In-Depth Interviews}

The in-depth interviews on which the qualitative analysis is based extend over a number of hours and may take place on more than one occasion. They have three main sections. The first inquires into the interviewee's history and life story. The second orients both the researcher and the interviewee to the specific topic of interest. The third draws these together in a reflexive dialogue about the meaning of the interviewee's experiences in light of his or her history (Rallis \& Rossman, 2003: p. 190)

The interviews are open-ended, searching for the themes of meaning in the participant's lives. They aim to understand the lived experiences of people. The main questions that guide the interview are: "what has this person experienced?" and "how does this person understand his or her experiences?" Qualitative analysis allows for a deeper appreciation of poverty's social context and its relationship to individual level intangibles such as values and attitudes.

\section{Analytical Procedures}

The paper brings together the demographic measures of fertility, a measure of chronic illnesses by socioeconomic status and qualitative interviews conducted around the themes of poverty, family and life experiences with select poor households across the country. Fertility was measured using parity of women aged $<15-30+$. Such a measure, of course, has its limitations, including the fact that it can not be used to foretell what the fertility of younger women that have not completed their childbearing will be. Furthermore, this measure is affected by a tendency on the part of older women not to report children who died shortly after birth. Finally, this measure of fertility is also affected by age misreporting. The data, though, allow for the study of fertility behaviour within the context of socioeconomic differentiation, something that is oft neglected in the study of demographic processes (Brown, 2000: pp. 1-3). Statistical analyses were done using cross tabulations. Statistical significance was established through the use of the Chi Squared measure.

Whereas quantitative data were used to establish associations between the variables mentioned above, qualitative case study material was used to do two things. Firstly, it allows for an understanding of how these might be reflected in the lived experiences of people. Secondly, it assists in identifying the mechanisms that might link the existence of poverty to some of the substantive issues that emerge from the quantitative analysis. The data were recorded during the interview and transcribed. Themes and issues salient to the research issues of poverty and 
its transmission across generations, social service delivery to the poor, the health status of the poor, mating and fertility patterns among the poor and the labour market experiences of the poor were identified.

\section{Social Policy Context: Social Monitoring and the Use of Quantitative and Qualitative Data in Poverty Research in the Caribbean}

The relationship of quantitative and qualitative approaches in research into poverty in the region, to time and place in Caribbean society, provides an interesting story. Examination of the use of the two methods in the study of Caribbean poverty over the past three decades or so takes us into the realm of the recent history of social policy in the region (Harison, 2011; Brown, 2003).

Close, systematic monitoring of the situation of the poor in the region in the modern period is associated with economic crisis that signaled the end of state-led attempts at development that had informed the first attempts at nation building in the immediate post independence period (Thomas, 1995: pp. 232233). The crisis of the late 1970s and the advent of marketdriven Structural Adjustment in the policy making circles, beginning in the late 1970's, meant the dawn of a new era in attempts at development and social policy formulation; one driven by the theoretical prescriptions of Economic Neo-liberalism (Levitt, 2006: p. 183; Klak, 1998: pp. 17-20).

In its practical dimensions, Economic Neo-liberalism is a macroeconomic management strategy informed by the notion that the problems associated with economies both in the North and the South that had started to emerge in the mid-1970s had to do with too much state intervention. The emphasis on efficiency in resource allocation through a minimalist regulation of the market came into ascendance in policy-making circles across the globe under the aegis of a political-institutional nexus that came to be known as the Washington consensus.

If "freedom from want" was replaced with "freedom to do" in this scenario, it was understood that the resulting social fall out, in the Southern hemisphere economies especially, would be short term and that it could be monitored and managed. Eventually, it was argued by the international financial institutions, the efficiencies released by the institutionalization of free market economics would lead to prosperity and well being for the lagging countries of the world such as the Anglophone Caribbean.

Economic neo-liberalism is based on the assumption that individualism in the market place will lead to order in the distribution and allocation of resources and rewards in the wider economy and society (Lal, 1991: p. 32). In the case of the Caribbean, therefore, the understanding of the international financial institutions was that the implementation of structural adjustment policies that hobbled the state and gave free reign to the private sector would lead to increases in social misery and material deprivation. They theorized that the impact of the measures would be short term and it would be corrected as the economy and society progressed on the path of neo-Liberal reform. Since structural adjustment is essentially a macroeconomic management strategy it is understandable that longer-term social development issues took a backseat to the exigencies of proper resource allocation.

For now, the immediate task was to put structural changes in place that would promote export oriented growth, reduce the role of government in the economy and ensure greater efficiencies in the use of existing resources. To monitor and manage the anticipated social fall out, quantitative Living Standard Measurement Surveys (LSMS) were institutionalized in a number of Caribbean countries. The institutional format in charge of the process in the case of Jamaica was a unit within the Planning Institute known as the Social Policy Development Unit. This unit, under the technical auspices of the World Bank, was charged with the responsibility of carrying out the LSMS and using the information to inform a social policy formulation process that would lead to greater efficiencies and effectiveness in the use of resources in the social sector.

There is much that can be said about this approach to social monitoring and intervention. It certainly represented a progression on the existing state of affairs that relied very little, if at all, on systematic survey data for the formulation of policy and the allocation of resources in the social sector. Apart from the decennial population census, the circumscribed labour force survey, the consumer price index and institutional based data that did not allow for proper targeting, the policies on the social sector were more often than not based on political exigencies and imperatives. ${ }^{1}$ Now household level data were available that allowed for a rational assessment of need in a number of social sector areas. The surveys also provided a basis for targeting and planning that had not existed before. Cost benefit analyses could now be done thus ensuring that scarce resources would be optimally utilized.

Institutionally, the qualitative approach to the study of poverty in the Caribbean emerged out of studies of poverty in the countries of the Eastern Caribbean sponsored by the Caribbean Development Bank (CDB). These studies have also been conducted in the Northern Caribbean in the British Dependencies of Turks and Caicos Islands, Cayman Islands and Anguilla. In these studies, the qualitative component (Participatory Poverty Assessment) is part of a far more holistic approach to understanding poverty than obtains in the case of the World Bank inspired studies. This incorporation of qualitative life narratives data into these studies was accompanied by some questioning of the usefulness of this data by senior policy makers and technocrats of the Caribbean Development Bank. Their main concern had to do with their inability to generalize from the findings of the qualitative data. This signaled a clear misunderstanding of the role of qualitative data in social research and seemed to mirror the emphasis placed on quantitative statistical analysis in the case of the World Bank sponsored studies.

\section{Rethinking the Role of the Social Sciences}

The qualitative approach to the study of poverty in Caribbean society is in accord with the new ways of understanding society that have emerged out of the rethink of development studies and the role of the social sciences in managing social and institutional changes in the Postcolonial world (Schuurman, 1993: pp. 16-32). This is in turn linked to the recent changes in global economy and the attempts of social science theory and by extension, method, to provide answers to some of the problems associated with these changes (Hoogvelt, 1998: pp. 116-120; Yeats, 2001: p. 17; Brohman, 1996: pp. 324-352; Preston, 1996; p. 273; Ramphall, 1994: pp. 42-61; 1997: pp. 1-30).

${ }^{1}$ One exception to this was a study of social needs conducted by the anthropologist M.G. Smith commissioned by the Michael Manley government in 1975. See Smith, M.G. (1982). 
The new theoretical thrust calls for an interpretive-critical dialogue that would represent a shift from the First World offering of technical expertise to the Third. This offering is based on the positivist mis-analysis of society and economy associated with neo-classical economics. The shift would enable an elucidatory interchange between both areas of an increasingly interconnected globe (Preston, 1996: pp. 329-330). This should be based on an understanding of social scientific enquiry devoid of argument by analogy between the natural and social sciences. In its place would be one that draws more on hermeneutic approaches to further the understanding of local perceptions and interpretations of what is deemed to be a much more complex process of social change than was previously thought.

The qualitative case studies used in the CDB studies provide a wealth of insight into the character of the society in which the individual lives. They tell of the social, cultural, economic, political and historical setting of which the respondent is a part. They also tell of the nature of the social relations and social network of the individual; how they have lived their lives; the decisions they have made and continue to make on a daily basis; and the interplay between culture, personality and society. The nature of these relations is, in part, a product of the inequalities that are related to the existence of poverty. They in turn serve to reinforce and perpetuate poverty. In sum, the interviews tell us of the circumstances that led to persons finding themselves in situations of insufficiency. They also tell of how people cope, adapt and adjust to such situations. At the end of the process an understanding of how deprivation has found expression in the lived experiences of the individual is obtained.

\section{Resolving the Epistemologies: Fitting Quantitative and Qualitative Data}

The quantitative data gleaned by the formal survey and household questionnaires and the data gleaned from the indepth household interviews are of course based on different approaches to the study of social reality (Polkinghorne, 1983: pp. 22-23; 1988: pp. 7-8) It is important though that the complementary nature of the two types of data be understood (Patton, 2002: pp. 49, 69). Einstein's famous quotation tells us that, “not everything that can be counted counts and not everything that counts can be counted". ${ }^{2}$ Joseph Stiglitz warns against making a "fetish out of metrics" (Stiglitz, 2009). These arguments seem to suggest the need for the creative application of both qualitative and quantitative methodologies in social research to address questions that causal-explanatory and interpretive-constructivist epistemologies cannot answer by themselves.

Their combination, it would seem, can lend much to enhancing our understanding of the causes and sustainers of social issues such as poverty as well as some of the corrective measures that can be employed in the area of policy. This can happen in two ways. Firstly, qualitative data in the form of extended discussion on a topic can alert us to measurable issues that are of significance that have not been measured. Secondly, qualitative data can enable us to understand meanings attributed to experiences that simply cannot be measured or quantified and yet are important for social outcomes. In the case of the Grenada data, two substantive issues are examined to see the extent to which their expression, as qualitative data, brings to the fore linkages between the variables that are not immediately obvious from an examination of the quantitative data. The is- sues are as follows:

1) Chronic illness and poverty; 2) intergenerational poverty, gender and the segmented labour market.

\section{Chronic Illnesses and Poverty}

In the analysis of the quantitative data gleaned from the household surveys of reported health in the Caribbean the poor have tended to report better health than the non-poor (Brown, 2006: pp. 55-77). This odd finding on reported health from the surveys points to a number of structural constraints and the kind of adaptation in attitude that is made by the poor of the region. Lack of resources means an inability or, at the very least, difficulties in accessing good quality medical care. This, coupled with the preoccupation with "making two ends meet", and a lack of knowledge about human physiology serves to undermine the development of a "check-up" culture, or a preventive approach towards health care. So, even as they report no ill health in the surveys the disease is often at work, but not yet manifest.

\section{The Case of Ms. Wendy}

This relationship between chronic illness and poverty that is obscured by the analysis of quantitative data is brought out quite clearly in the qualitative. This takes the form of the narrative that comes out of the in-depth interview conducted with Ms. Wendy, a 54-year-old single mother of 9. Her illnesses are chronic, lifestyle-based, silent killer diseases. Given her stressful circumstances of deprivation, low levels of education and her health care seeking behaviour it is perhaps no wonder that she came down with the two diseases that she did and that they both took her by surprise.

When she is interviewed, Ms. Wendy provides insight into the nature of her health seeking behaviour and how it might be related to the underestimation of the incidence of the silent illness by the poor. She indicates that she does not go to the doctor unless she is feeling unwell. The nature of chronic noncommunicable illnesses, such as hypertension, diabetes and the more immediately life threatening cancer, is such that to wait until symptoms start appearing is usually too late to take effective control of the disease. She attributes her approach to health care to the hardship that she faces in life and the difficulty she encounters, on a daily basis, in providing the basic needs of her life. In addition to material deprivation, in many instances the daily tasks of the working poor are so consuming that they find themselves suffering serious time poverty as well. Health concerns that are not immediately disruptive to their routine are unlikely to be at the top of their agenda when it comes to decisions relating to the daily allocation of time specific tasks. The unfortunate thing, as Ms. Wendy discovers, is that delaying health care seeking now is likely to lead to greater illness later on. Therefore, even as the poor are becoming more unwell as a result of these chronic illnesses, the quantitative data are indicating that their health status is better than the non-poor. This is illustrated in Table 1.

The table is based on self-reported information. It reveals, in the case of the silent, chronic illnesses, what appears to be a serious undercount on the part of the three lowest quintiles. The undercount is particularly pronounced in the case of the poorest quintile, the one in which Ms. Wendy would fall. Note that in the case of asthma, which is a very "noisy" disease, the socioeconomic differential virtually disappears. This means that the 
Table 1.

Distribution of chronic illnesses by quintile, Grenada.

\begin{tabular}{ccccccc}
\hline Type of & \multicolumn{6}{c}{ Consumption Quintiles (Percentages) } \\
\cline { 2 - 7 } $\begin{array}{c}\text { Chronic } \\
\text { Illness }\end{array}$ & I & II & III & IV & V & Total \\
\hline Diabetes & 8.0 & 10.2 & 17.5 & 23.5 & 40.8 & 100.0 \\
$\begin{array}{c}\text { High Blood } \\
\text { Pressure }\end{array}$ & 5.2 & 12.4 & 20.2 & 25.7 & 36.5 & 100.0 \\
$\begin{array}{c}\text { Heart } \\
\text { Condition }\end{array}$ & 5.6 & 18.1 & 12.2 & 25.0 & 39.2 & 100.0 \\
Cancer & .0 & 37.9 & 14.9 & 11.5 & 35.7 & 100.0 \\
HIV/AIDS & .0 & .0 & .0 & .0 & .0 & .0 \\
Asthma & 15.7 & 28.7 & 14.2 & 24.9 & 16.5 & 100.0 \\
Other & 4.9 & 25.7 & 16.2 & 32.6 & 20.6 & 100.0 \\
Not Stated & .0 & 14.9 & 46.7 & 23.6 & 14.9 & 100.0 \\
Total & 7.9 & 15.3 & 18.7 & 26.0 & 32.1 & 100.0 \\
\hline
\end{tabular}

Source: Grenada Country Poverty Assessment 2008. Pearson's Chi-Square 2546.522; Df 28; Significance .000.

circumstances of poor persons make them particularly vulnerable to the worst effects of the silent, lifestyle illnesses. In summary terms, low levels of income, stress, poor diet, bad healthcare seeking behaviour and quite possibly poor quality health care are the factors that seem to be at work in Ms. Wendy's case. Ms. Wendy does not point to the quality of health care as a factor, but given the comments made by community members, who speak of the doctor writing the prescription "as they enter the door", it might very well be a factor.

In this case therefore, the quantitative analysis by itself, far from providing a proper understanding of the relationship between social phenomena, actually obfuscates it. There is no statistical technique that applied to this data would change the fact that the underlying epistemology associated with it does not allow for the capture of the complex interplay between structural imperatives and lived experiences.

\section{Intergenerational Poverty, Gender and the Segmented Labour Market}

The quantitative data collected by the surveys provide the basis for the calculation of poverty lines. Calculated over time, these provide policy makers with a sense of how their major economic and social initiatives affect the well being of poor households. This calculation, though, aggregates a number of categories of poor persons. Thus, for example, there is no immediate indication of what proportion of the households falling below the line are recently poor or have been poor for generations.

Where panel data are available, it is possible to do these calculations. Indeed, in the largest of the territories of the regionJamaica, the availability of such data has allowed for the calculation of household movement into and out of poverty over relatively short periods of time. However, in the context of scarcity of resources and underdeveloped statistical infrastructure that often characterize the smaller territories, the data to conduct this type of analysis are not often available. Furthermore, the available data on these households do not allow for the capture of the institutional interface that provides the context within which chronic, long -term poverty operates.
The extended interviews conducted among the poor and non-poor households allow for the identification of households that have been poor for differing durations. They bring to the fore, as well, the variables of intergenerational poverty, gender and the segmented labour market. The case studies have provided information that suggests that intergenerational poverty occupies a significant position in the Caribbean's socioeconomic landscape. Given the nature of the region's historical political economy this should come as little surprise (Beckford, 1972). The question that arises though is what is the nature of the mechanisms operating at the level of the individual and the household that are responsible for the reproduction of poverty across the generations?

The information coming out of the in-depth household interviews seem to suggest that one important mechanism is the mating and family formation patterns of these households. The causal status of this factor is not immediately evident. What is apparent is that it is related to low levels of education, family situations in which young females lack the emotional and material support of a male and a primary labour market segmented along the lines of gender. The pattern of early pregnancy as a precursor to repeated pregnancies with short birth space intervals is evident in the lives of virtually all of the women encountered in these case studies. The relation of this fertility pattern to their socioeconomic status is evident from an examination of the table below. The socioeconomic differential in this measure of fertility behaviour would be repeated in virtually any measure of fertility that is used.

At the aggregate level these populations evince signs of demographic transition with a marked reduction in births and very low rates of mortality. Poor women, however, have been left behind, caught in a time warp, so to speak. They still produce, as their mothers before them did, relatively large families tied, as we have seen, to early pregnancy and repeated child bearing with short birth intervals. This of course significantly reduces their life chances through curtailing their education and restraining them from as full and active a participation in the labour market than would otherwise have been possible. Table 2 illustrates this reproductive pattern.

The most noteworthy feature of the table is the marked differential between rich and poor when it comes to fertility behaviour. What the case studies alert us to is the interface between agency and structure and its outcome in terms of fertility

Table 2.

Age at first birth by consumption quintile, Grenada females.

\begin{tabular}{ccccccc}
\hline \multirow{2}{*}{$\begin{array}{c}\text { Age at First } \\
\text { Birth }\end{array}$} & \multicolumn{5}{c}{ Consumption Quintiles (Percentages) } \\
\cline { 2 - 7 } & I & II & III & IV & V & Total \\
\hline Under 15 & 4.6 & .9 & 7.7 & 6.2 & .0 & 4.0 \\
$15-19$ & 57.8 & 45.6 & 34.3 & 31.2 & 25.0 & 40.3 \\
$20-24$ & 13.2 & 26.8 & 29.5 & 25.4 & 33.2 & 24.8 \\
$25-29$ & 2.4 & 8.1 & 5.6 & 13.1 & 11.1 & 7.7 \\
$30+$ & 1.1 & 1.2 & 3.6 & 6.6 & 15.6 & 4.9 \\
Not Stated & 21.0 & 17.4 & 19.3 & 17.4 & 15.2 & 18.3 \\
Total & 100.0 & 100.0 & 100.0 & 100.0 & 100.0 & 100.0 \\
\hline
\end{tabular}

Source: Grenada Country Poverty Assessment 2008; Pearson’s Chi-Square 2632.904; Df 20; Significance .000 
differentials across socioeconomic status. The problem of high levels of fertility among poor women that is signaled by the data contained in the table is easily understood in personal terms when we look at the case studies. It ceases to be a personal or psychological issue, though, when entire social strata in the society, faced with the constraints of low levels of education and a segmented primary labour market, take the decisions relating to reproductive behaviour that are manifest in the differentials evident in Table 2.

The socioeconomic differential in fertility patterns is most evident in the women aged 15 - 19 years. Here more than one half of the poorest women have experienced the birth of their first child. This compares to 25 percent of the women in the wealthiest quintile. The pattern is reversed in the $30+$ age group where a mere one percent of the poorest women are having their first birth as opposed to 16 percent of the women in the wealthiest quintile.

How is this socioeconomic differential in fertility related to the segmented primary labour market? What do the qualitative data tell us about this process that the quantitative data do not?

\section{The Case of Leroy and Phiona}

Leroy is a 41-year-old father of two children and temporary partner of Phiona, who is a temporarily employed 44-year-old mother of five.

The interviews with Phiona and Leroy point to the dynamic between chronic poverty, the labour market, family formation and gender. Phiona has inherited her deprivation from her own family. At 44, with little or no marketable skills, she finds herself with 5 children and very little support from their fathers. Leroy, at 41 , is the father of two children with women in another part of the country. He is a migrant labourer, temporarily living in Phiona's district to do a job. Leroy is mindful of the responsibilities of being involved in a relationship with a woman. He says sometimes he has to starve himself to meet these obligations. Therefore he is not actively seeking such a relationship. However, he occupies a relatively advantageous position in the primary labour market to which both he and Phiona belong. Phiona on the other hand is relatively disadvantaged by this market and finds herself in a position of great vulnerability. He therefore becomes fair game for her entreaties and soon succumbs to them. Despite all of the structural constraints with which he is faced, temporary employment, relatively low wages, responsibilities to his other children, and the need to now provide for Phiona's household, he enters into a relationship with her, even while protesting that he had had no intention of doing so originally.

The experiences of Leroy and Phiona reflect the dictates and logic of a dynamic that consists of a synergism of a number of factors. These are: a mating system in which the initiation of a sexual relationship between a man and woman, in some local ecologies, has loose social, but no legal sanction; inadequate provision for the physical and in some instances emotional nurturing of the young; lack of preparation for effective participation in the labour market; and economies relegated to positions of marginality within the global chain of production.

The experiences of these two persons also suggest that at the level of the individual, gender mediates this dynamic. Men experience it differently from women. However, both should be understood to be its victims. The primary labour market, for cultural reasons, favours the participation of men over women.
Nonetheless, it is still a primary labour market with all of the insecurities of tenure, low level skill requirements, low pay and so on. Men, therefore, although favoured by this market are still subject to its deficiencies. Therefore, they are more likely than women to get work and therefore be in a position to make offers to the disadvantaged woman. However, the nature of the work does not provide the level and stability of income to enable the man to make a sustained contribution to the upkeep of a family.

Because of this, many poor men, as in Leroy's case, become migratory labourers within their own country, moving in search of uncertain work. Because of the transitory nature of their stay, they are even less encumbered by what in many instances are already loose social sanctions pertaining to the initiation of sexual relationships between men and women. The poorest women in these locales are open to the overtures of men who, at least temporarily, have a source of income. The presence of women made readily available because of their vulnerable socioeconomic position is the basis on which these types of unstable relationships rest.

There are some men that choose not to become migratory workers. For them this means an employment situation that is at best tenuous. This holds implications for their ability to provide for their children, in spite of their best intentions. Even in situations of steady and sustained incomes, the relatively disadvantaged position of women in the primary labour market increases their vulnerability and contributes to the creation of a pool of readily available women that lends instability to existing unions.

One thing that is noticeable is that the women having births in their teens in these studies are from households marked by unstable relationships between the principals. Ms. Wendy and Phiona lacked the emotional security and protection that should normally attend a young woman's development. They both came from households marked by high levels of deprivation and which did not provide the emotional and material security that underpins stable psychosocial development.

\section{The Case of Marie}

The case studies provide us with a measure of insight into how these factors play themselves out in the lives of these women. Take the case of Marie, for instance. She is a 49-yearold mother of 10 . She began her mating experiences in what is characterized by Caribbean demographers as a "visiting" relationship. She produced two children within this union type. She then moved into a common-law (cohabitive) relationship with the same man and bore him two more children before returning to a visiting relationship with another man for whom she then had five children. Subsequently, she entered into a common law relationship with a third man for whom she bore one child. She presently lives by herself with some of the children from these relationships.

Marie notes the seeming irresponsibility of the men who fathered her children. Yet, she notes the obvious love they have for their children. It is this contradiction that alerts us to the existence of structural constraints that override even the best of intent in human will.

\section{Conclusion}

The paper has examined two dimensions of Caribbean pov- 
erty to see to what extent there is complementarity between quantitative and qualitative data, with their distinctive epistemological bases. The two areas of focus were chronic illness and poverty and intergenerational poverty and the factors related to its reproduction. In the case of chronic illnesses and poverty the qualitative data point to the inadequacy of the variable of "reported health" used in the quantitative approach. In the case of intergenerational poverty, gender and the segmented labour market, the qualitative data allow for an understanding of the synergism of factors that are not evident from the quantitative analysis.

The paper has demonstrated that even while respecting the distinctiveness of the philosophical bases of the two approaches to the study of social phenomena, the understanding of poverty in the region can be furthered by recognition of the complementarity that inheres in them.

\section{REFERENCES}

Beckford, G. (1972). Persistent poverty: Underdevelopment in plantation economies of the Third World. Oxford: Oxford University Press.

Brohman, J. (1996). Popular development: Rethinking the theory and practice of development. Cambridge, MA: Oxford University Press.

Brown, D. A. V. (2002). The political economy of fertility in the British West Indies 1891-1921. Kingston, Jamaica: University of the West Indies Press.

Brown, D. A. V. (2003). Social policy in the Caribbean, its history and development: The evolution of social policy and its modern influences in the Caribbean. Santiago, Chile: United Nations Economic Commission for Latin America and the Caribbean (UNECLAC).

Brown, D. A. V. (2006). Reported health and poverty in the Caribbean: How useful are the LSMS Data? Social and Economic Studies, 55, 55-77.

Brown, D. A. V. (2011). Chronic poverty, mating and fertility in the Caribbean. In B. Masquelier, \& T. Eggerickx (Eds.), Dynamiques de pauvretés et vulnérabilités en démographie et en sciences sociales (pp. 165-186). Actes de la Chaire Quetelet, Presses Universitaires de Louvain.

Brown, D. A. V. (2011). Structural adjustment and the neglect of intergenerational poverty in the Caribbean. In D. A. V. Brown et al. (Eds.), Strategies against poverty: Designs from the North alternatives from the South (pp. 189-218). CLACSO-CROP.

Kairi Consultants Limited (2008). Country poverty assessment: Grenada, Carriacou and Petit Martinique. Barbados: Caribbean Development Bank.

Grosh, M., \& Glewwe, P. (1995). A guide to Living Standard Measurement Surveys and their data sets. LSMS Working Paper \#120: World Bank.

Harison, J. (2011). The colonial legacy and social policy in the British Caribbean. In J. Midgley, \& Piachaud (Eds.), Colonialism and welfare: Social policy and the British imperial legacy. Cheltenham: Edward Elgar Publishers

Hoogvelt, A. (1998). Globalization and the postcolonial world. London:
Macmillan.

Klak, T. (Ed.) (1998). Globalization and neoliberalism: The Caribbean context. Maryland: Rowman \& Littlefield Publishers.

Lal, D. (1996). Ch. 2: The misconceptions of development economics. In C. K. Wilber, \& K. P. Jameson (Eds.), The political economy of development and underdevelopment. New York: McGraw-Hill.

Martinussen, J. (1997). Society, state and the market. London \& New York: Zed Books.

Patton, M. Q. (2002). Qualitative research and evaluative methods (3rd ed.). London: Sage Publications.

Polkinghorne, D. (1983). Methodology for the human sciences: Systems of inquiry. New York: State University of New York Press.

Polkinghorne, D. (1988). Narrative knowing and the human sciences. New York: State University of New York Press.

Preston, P. W. (1996). Development theory: An introduction. Oxford: Blackwell.

Rallis, S. F., \& Rossman, G. B. (2003) Learning in the field: An introduction to qualitative research (2nd ed.). Thousand Oaks, CA: SAGE

Ramphall, D. (1997). Postmodernism and the rewriting of Caribbean radical development thinking. Social and Economic Studies, 46, 130.

Ramphall, D. (1994). Rethinking poverty and development policy in the Caribbean in the age of globalization. In H. Watson (Ed.), Human resources and institutional requirements for global adjustments: Strategies for the Caribbean: Special issue of 21st century policy review (pp. 1-2, 42-61).

Rist, G. (2003). The history of development: From western origins to global faith (Expanded ed.). London: Zed Books.

Rostow, W. W. (1960). The stages of economic growth: A non-communist manifesto. Cambridge: Cambridge University Press.

Schuurman, F. (1993) Beyond the impasse: New directions in development theory. London: Zed Books.

Stewart, F. (1985). The fragile foundations of the neoclassical approach to development. Journal of Development Studies, 21, 282-292. doi:10.1080/00220388508421943

Smith, M. G. (1982). Poverty in Jamaica. Social and Economic Studies, 31.

Stiglitz, J. (2009). Economic performance and social well-being. In Distinguished open lecture series. St. Augustine Campus: The University of the West Indies.

Stiglitz, J. (2009). GDP fetishism. http://www.project-syndicate.org/commentary/gdp-fetishism

Thomas, M., \& Wint, E. (2002). Inequality and poverty in the Eastern Caribbean. ECCB Seventh Annual Development Conference, St. Kitts.

Thomas, C. Y. (1995). The crisis of development theory and practice: A Caribbean perspective. In K. Levitt, \& M. Witter (Eds.), The critical tradition of Caribbean political economy: The legacy of George Beckford. Kingston, Jamaica: Ian Randle Publications.

World Bank. Living Standard Measurement Survey. http://go.worldbank.org/WKOXNZV3X0

Yeates, N. (2001). Globalization and social policy. London: Sage Publications. 